\title{
The Effectiveness of Targeted Music Therapy Intervention and Cognitive-Behavioral Therapy on Sleep Quality and Symptoms of Insomnia Disorder in seniors
}

\author{
Reza Mottaghi ${ }^{1}$, Ali Kamkar², Alireza Mardpoor ${ }^{3}$
}

\section{ABSTRACT}

Context and Objective: Due to the high prevalence of sleep disorder in seniors, this study focuses on the effect of objective music therapy or MAT and cognitive-behavioral therapy or CBT on overall sleep quality and subscale indexes of sleep quality in seniors.

Methodology: The present study is an experimental one with random selection of the subjects. The sample study is taken from 5000 senior member's if Shiraz's Jahandedehgan day care center. This study holds 66 subjects containing the entry and exclusion criteria. Following 7.85 percent loss, 61 seniors suffering from primary insomnia disorder and mean age of 68.15 were placed into three groups, two experimental and one control group. The experimental group one takes part in musical and cognitivebehavioral group therapy and the experimental group two takes part in cognitive-behavioral group therapy while the last group received no intervention. All patients in this study were measured for the level of disorder and before and after the treatment using the PSQI scale of insomnia disorder. The collected data were measured by statistical software SPSS 21 and were analyzed by multivariate analysis of covariance or MANCOVA and ANCOVA.

Findings: The mean of overall sleep quality before the intervention in experimental groups $1 \& 2$ and control were 13/31, 12/95, and 12/7 respectively and were changed into 13.31, 9.73, and 7.59 after the intervention in post-test and finally in the 3 months follow-ups the means become 7.22, 9.32, and 13.55. The mean difference in the overall sleep quality after the intervention and the subscale indexes were significant as The result showed musical therapy and cognitive behavioral caused a significant reduction on the patients with the symptoms of insomnia disorder $(\mathrm{P}<0.001)$.

Conclusion: The present study shows that music therapy and cognitive-behavioral therapy are more effective in developing overall sleep quality and decreasing the symptoms of insomnia disorder in seniors than the cognitive-behavioral therapy alone. Using this method by experts in the field of mental health and elderly care companions is strongly recommended.

Trial registration: This study is registered in the IRCT Register, IRCT2015041521754N3. Ethical approval was gained in June 2015.

Keywords: Insomnia disorder, Music therapy, cognitive behavioral therapy, seniors.

\footnotetext{
${ }^{1}$ Music therapist and MA in Clinical Psychology, Islamic Azad University, Yasouj branch, Iran

${ }^{2} \mathrm{PhD}$ in Psychology, Faculty of Medical Science, Yasouj, Iran

${ }^{3}$ PhD in Psychology, Faculty of Islamic Azad University, Yasouj branch, Iran

(C) 2015 I R Mottaghi, A Kamkar, A Mardpoor; licensee IJIP. This is an Open Access Research distributed under the terms of the Creative Commons Attribution License (http://creativecommons.org/licenses/by/2.0), which permits unrestricted use, distribution, and reproduction in any Medium, provided the original work is properly cited.
} 


\section{The Effectiveness of Targeted Music Therapy Intervention and Cognitive-Behavioral Therapy on Sleep Quality and Symptoms of Insomnia Disorder in seniors}

Sleeping comes to be one of the important aspects of life that includes almost one-third of human's whole life. The importance of sleeping is nothing strange for the people as it comes to be a necessary element in life which also helps in brain functioning as well. Insomnia disorder might causes damages on the quality of daily chorus and eventually leads to exhaustion, anger, irritability, Para amnesia, concentrating problems and mood changing [1]-[2]. Insomnia comes to be a major problem in majority of people since this phenomenon is increasing among children, teenagers, adults and specifically in seniors with the highest percentage [3]. Aging is a reality that cannot be ignored any longer by the physicians. According to the statistics the senior population over 60 will reach 1.2 billion in 2025 and will be doubled in 2050 [4]-[5].

Sleep disorder is divided into two categories; primary and secondary. The primary insomnia is not related to any mental or physical disorders or drugs. Patients main complain are their difficulty initiating, stability and continuity of sleep and lack of comfort ability the following day in a period of one month [6]-[7]. Insomnia disorder in senior might lead to depression, falling out and physical and mental problems [8]. The outcome of insomnia and other sleep disorders are much more serious that people think about, these patients do not only suffer from a bad night sleep, but their work efficiency will be reduced due to their lack of energy [5]-[9]-[10].

Since insomnia disorder affects the quality and efficiency of life and work in the worst way possible, many physicians and experts tried to find a perfect cure for this situation. The most inflectional treatments that have been introduced to the world so far are medications and Cognitive-behavioral therapy which is known as CBT. Among the prescribed medications, Benzodiazepines and anti-depression medications are the most popular treatments for insomnia disorders [11]-[12]. Meanwhile these medical treatments are applied on 15 to 19 percent of the seniors with the following side effects including tiredness and sleepy in daylight, lack of tolerance, dependence to the pills, altered time of sleep and insomnia. Based on this result many studies have been conducted to analyze the efficiency of these treatments on seniors. Meanwhile other alternative non-drug approaches are now considered [3]-[13].

Cognitive-behavioral therapy, believes to be one of the popular non-medical treatments, which is now considered as one of the useful approaches for treating insomnia for seniors in the past a few decades [14]-[15]-[16]. However music therapy comes as another non-medical approaches in insomnia treatment. Music therapy comes as a joyful, cheap, easy and comfortable treatment that presents its effects in a short period of time. Sedative music causes relaxation and sedative responses, which will reduce the activity of neuroendocrine and Sympathetic nervous system that eventually controls anxiety heart rate, respiratory rate and blood pressure. Music also has a great influence on decreasing the noradrenalin in blood circulation that plays an important role in initiating sleep. Therefore it seems that a sedative music therapy will help in developing a perfect sleep [3]-[17]-[18]. In general by using both approaches; music therapy and cognitive-behavioral therapy together the results concerning the improvement of sleep quality can be promising.

Cognitive-behavioral therapy or CBT presented its effectiveness in insomnia treatment and captured the attention of the experts in past decades [16] and at the same time the presence and effect of the music therapy or MAT is also noticeable [17]. While joining these two approaches might be challenge, but at the same time it have its own benefits. It seems that music therapy targets emotions and feelings of the patient in a way that effects the interaction of thought, 


\section{The Effectiveness of Targeted Music Therapy Intervention and Cognitive-Behavioral Therapy on Sleep Quality and Symptoms of Insomnia Disorder in seniors}

feeling and behavior, the main consideration of the cognitive-behavioral therapy. Therefore MAT can become beneficial in the CBT approaches as well [19]-[20]. Using a sedative music before bedtime and energetic and live music for daylight can bring a calm night and vitality day life, while performing live music sessions in group therapies might also have beneficial effects in treating insomnia as well [21]-[22]-[23].

\section{METHODOLOGY, TARGET POPULATION AND SAMPLING}

This study uses the pre-test, post-test and follow-ups after 3 months of intervention with the control group as its methodology. Three groups in three stages as music therapy or MAT and cognitive-behavioral therapy or CBT presented as the independent variable while the overall quality of sleep and the subscales including subjective sleep quality, sleep latency, sleep duration, sleep efficiency, sleep disorder, use of sleep medication and daytime dysfunction presented as the dependent variables.

The population of this study consists of seniors over 60 with primary insomnia disorder having entry conditions such as being a member of Shiraz Jahandedehgan adult day center, diagnosed with primary insomnia disorder, willing to participate, smoke less than 10 string a day, below 80 percent sleep efficiency, achieved score 5 in sleep quality based on PSQI, literacy, written consent for attending the treatment program. The exclusion condition of this program includes having secondary sleep disorder, medical problems that leads to insomnia and unwillingness to follow the treatments and finally death [24].

The presented study contains 66 subjects, 9 male and 57 female with age mean 68.08 and $\mathrm{SD}=6.18$ with primary insomnia disorder that were chosen randomly. Shiraz adult day center hosts 5000 members, that were informed about the program and 300 people were admitted and only 100 were diagnosed with primary insomnia disorder. Among the selected adults, 66 subjects were chosen randomly and placed into three groups; two experimental and one control each consist of 22 participants. Finally with the loss of 7/58 percent the total amount of participants become 61 as the experimental group one or the (MAT) hold 22 subjects, experimental group two or the (CBT) hold 19 subjects and the control group holds 20 subjects. As shown in chart 1. After analyzing, the findings suggested that the sample size for the experimental and control groups were sufficient [25]. Both experimental groups went under 4week intervention and the control group received no intervention at all. PSQI scale was used to analyze and study the participants in pre-test, after test and follow-ups after the treatments, while both experimental groups received cognitive behavior therapy intervention, but only experimental group one received music therapy intervention as well.

Tools of Measurements: The Pittsburgh Sleep Quality or PSQI questionnaires were conducted by J. Bass and et al. to measure the sleep quality and help to diagnosis people who sleep well or bad [24]. This 18 questionnaire scale is a report containing 7subscales including subjective sleep quality, sleep latency, sleep duration, sleep efficiency, sleep disorder, use of sleep medication and daytime dysfunction Each subscale holds grade from 0 to 3 and the overall rating of the 7 components to measure the overall quality of sleep covers from 0 to 21 [26]. 

Quality and Symptoms of Insomnia Disorder in seniors

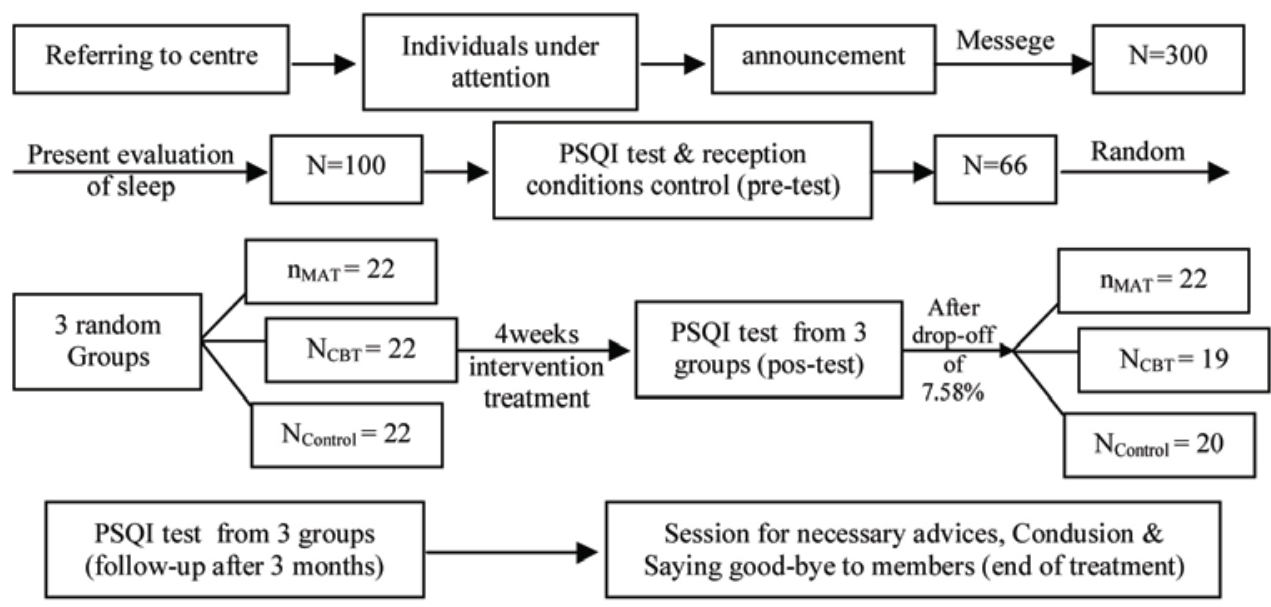

Flow chart 1. Overall plan for methodology.

\section{METHODOLOGY AND ANALYSIS}

After performing the pre-test and random selection of the participants and placing them into experimental groups $1 \& 2$ and a control group of 22 subjects; a cognitive behavior intervention was performed on both experimental groups separately based on the Espie instruction twice a week in a period of four weeks [27]. First Week: Explaining the educational goals and meeting members, make an agreement about the time and place, reminding them the importance of the medical duties, analyzing the problem of the insomnia, realizing sleep and insomnia, analyzing thoughts, teaching relaxation and assignments (sleep calendar, worksheet on concerns). Second Week: Sleep hygiene and relaxation, new timeline for sleep, sleep restriction, preventing daily naps, food hygiene and assignments (sleep calendar, worksheet on concerns). Third Week: Problem solving, organizing thoughts, reality of sleep, circulation of thoughts, feelings and behaviors, teaching to block thoughts, imagination, relation and avoid veining tries to sleep, opposite planning and using all instructions of the previous meetings and assignments (sleep calendar, worksheet on concerns). Fourth Week: Presenting the whole treatment plan and CBT, sleep hygiene, cognitive behavior intervention, noticing the development of the treatment according to the sleep calendar of the patients.

Musical therapy intervention is applied only to the experimental group one, as the patients received a CD containing a sedative music for nights which is used 45 minutes before going to sleep, an energetic music for mornings to be alive and vital which will be used based on the needs and desire of the patients. Alongside these interventions there will be a relaxation programs alongside the treatments as well [28]. Immediately after intervention a proper sedative music will be performed for the patients and the recorded music will be handed over to them, in order for the patients to listen to it before going to sleep to gain relaxation. In another word we used simple conditioning method for the patients using music, as it shown in chart 2. After 4weeks of intervention an after-test were taken from both experimental groups and the control group and a date for three months later were set, after three months another test were taken and final instructions were given to the patients and we left the center. 


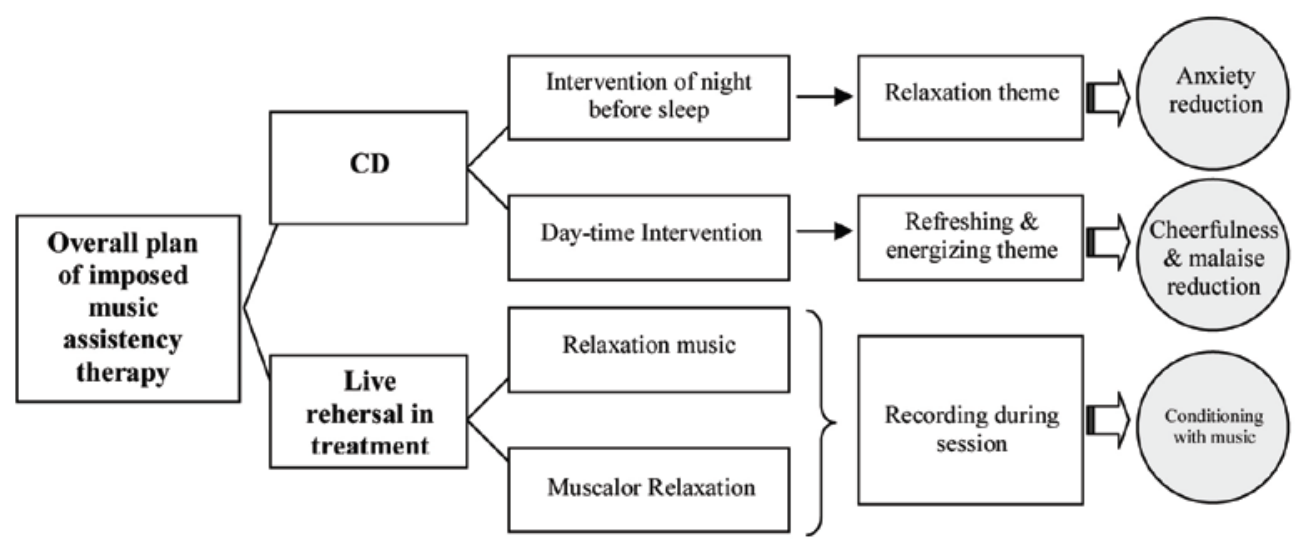

Flow chart 2. Music Assistency therapy intervention overall plan.

\section{SUMMARY OF THE HYPOTHESIS}

The presented data gathered from this study were analyzed using covariance or MANCOVA and ANCOVA and SPSS 21 statistical software. Before analyzing the hypothesis data, in order to realize that the presented data of this study will perform the underlying hypothesis of covariance analysis, first we analyzed underlying hypothesis alone. Therefore it is necessary to study the underlying hypothesis of covariance including linearity, homogeneity of variance, homogeneity of variance-covariance matrix and homogeneity of regression. For the matter of analyzing simple covariance, only linearity and homogeneity of regression and homogeneity of variance is required. Since the sample size in both experimental groups and control is almost equal, the underlying hypothesis of homogeneity of variance-covariance matrix and M-BOX test had no significant effect on the final results and therefore it can be eliminated. Finally with a proper study the underlying hypothesis for analyzing covariance is applied. [25]-[29]. In this part of the study, related descriptive analytical findings of the study will be presented to the readers.

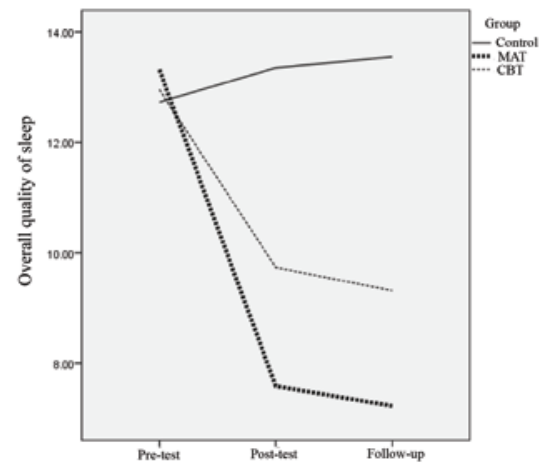

Graph 1. Comparison of Groups means in pre-test, post-test and follow-up in overall quality of sleep variable.

\section{FINDINGS}

The demographic findings of this study shows that female population is above the male population as there were 14.75 percent male population and 85.25 percent female ones. Mean age or SD of the experimental groups one with music therapy and one with cognitive-behavioral 


\section{The Effectiveness of Targeted Music Therapy Intervention and Cognitive-Behavioral Therapy on Sleep Quality and Symptoms of Insomnia Disorder in seniors}

group and also the control group will be 68.59 (6.59), 69.21 (5.95) and 66.70 (5.89) respectively. Most participants had high-school education degree and their physical activities were more moderate as it was 50.82 percent. None of the participants smoked and 55.74 percent were married and the rest were single.

To study the effect of music therapy and cognitive behavior intervention on the overall quality of sleep, we used one-way ANCOVA on two independent variables "post-test overall quality of sleep" and "follow-up the overall quality of sleep" [25]. The result shown in table 2 shows that after adjusting post-test and follow-ups scores using elimination of the pre-test, the intervention in both times post-test $(\mathrm{P}<0.001, \mathrm{~F}=41.64)$ and follow-ups $(\mathrm{P}<0.001, \mathrm{~F}=48.05)$ are significant.

The result of comparing Bonferroni means showed that in post-test and follow-ups, there is a significant difference among the three groups of music therapy, cognitive behavior therapy and control. This actually means that both musical therapy and cognitive-behavioral therapy were effective or in other terms the intervention is effective. Second of all due to the low mean of overall quality of sleep in music therapy to cognitive behavior therapy we can say that in the post-test and follow-ups the effect of music therapy is more significant than the cognitive behavior therapy, although cognitive behavior also has a significant difference with the control group.

Multivariate covariance analysis or MANCOVA was used in order to study of the secondary hypothesis subscales [25]. According to the results, the effect of groups on linear combination of the dependent variable by Wilks Lambda index in table 3 shows that $\mathrm{P}<0.001, \mathrm{~F}=4.2$ in post-test and $\mathrm{P}<0.001, \mathrm{~F}=6.96$. This means that there is a significant difference between groups. Statistical analysis of covariance univariate in each dependent variable and subscales were measured separately in order to determine a meaningful statistical data source of multivariate variables. Table 4 shows that after controlling the effect of pre-tests, the group effect in all posttestes and subscale indexes and follow-ups except sleep disorder were meaningful. In another term all post-tests and follow-ups except for insomnia there is at least a couple of significant differences among the means of each group exists. A pair comparison was used for a closer understanding that between the mean of each pair of groups in post-tests and follow-ups exists a significance difference.

According to the pair comparison findings, the most effect on the subscales were applied by music therapy and followed by cognitive-behavioral therapy. Based on the results music therapy group had a significant effect on all the subscales in post-tests and the effect were remained until the follow-up tests except for sleep disorder. But cognitive-behavioral therapy had effect only on sleep duration in post-tests and on subjective sleep quality, sleeps latency, sleeps duration and sleep sufficiency in follow-up tests, but it did not have any significant effect on subscales including insomnia, using sleeping medication and daytime dysfunction. 
The Effectiveness of Targeted Music Therapy Intervention and Cognitive-Behavioral Therapy on Sleep Quality and Symptoms of Insomnia Disorder in seniors

Table 1. Companison of means Standard deviation of Groups in pre-test, post-test \& follow-up

\begin{tabular}{|c|c|c|c|c|}
\hline $\begin{array}{c}\text { Independent } \\
\text { Variable }\end{array}$ & Groups & Pre: X(SD) & Post: $\mathrm{X}(\mathrm{SD}) \mathrm{P}<$ & Follow-up: X(SD)P< \\
\hline \multirow{3}{*}{$\begin{array}{l}\text { Overall quality of } \\
\text { sleep }\end{array}$} & MAT & $13.31(2.45)$ & 7.59 (2.58) $0.001 *$ & $7.22(2.75) 0.001 *$ \\
\hline & CBT & 12.95 (2.73) & 9.73 (2.21) 0.001 * & 9.32 (2.11) $0.001^{*}$ \\
\hline & Control & $12.7(2.96)$ & $13.35(2.71)$ & $13.55(2.28)$ \\
\hline \multirow{3}{*}{$\begin{array}{l}\text { Subjective sleep } \\
\text { quality }\end{array}$} & MAT & $1.6(0.7)$ & $0.77(0.53) 0.001 *$ & 0.54 (0.51) 0.001* \\
\hline & CBT & $1.7(0.7)$ & $1.32(0.67) 1$ & $0.95(0.52) 0.001 *$ \\
\hline & Control & $1.5(0.8)$ & $1.6(0.75)$ & $1.85(0.67)$ \\
\hline \multirow{3}{*}{ Sleep Latency } & MAT & $4.2(0.5)$ & $1.23(0.61) 0.001 *$ & $1.13(0.64) 0.001 *$ \\
\hline & CBT & $1.9(0.9)$ & $1.26(0.56) 0.075$ & $1.26(0.45) 0.004$ * \\
\hline & Control & $2.4(0.6)$ & $2.2(0.89)$ & $2.2(0.70)$ \\
\hline \multirow{3}{*}{ Sleep Duration } & MAT & $2.5(0.7)$ & $1.86(0.47) 0.001 *$ & $1.91(0.43) 0.001 *$ \\
\hline & CBT & $2.3(0.6)$ & $2.05(0.40) 0.01 *$ & $1.84(0.69) 0.001$ * \\
\hline & Control & $2.5(0.6)$ & $2.65(0.49)$ & $2.65(0.49)$ \\
\hline \multirow{3}{*}{ Sleep efficiency } & MAT & $1.7(1.1)$ & $0.86(1.08) 0.001 *$ & $1.04(0.84) 0.001 *$ \\
\hline & CBT & $1.4(1.1)$ & 1.32 (1) 0.124 & 1.68 (0.95) $0.01 *$ \\
\hline & Control & $1.5(1.3)$ & 2.05 (1.19) & $2.8(0.41)$ \\
\hline \multirow{3}{*}{ Sleep disturbance } & MAT & $2(0.6)$ & $1.36(0.49) 0.012 *$ & $1.36(0.66) 1$ \\
\hline & CBT & $2.2(0.6)$ & 1.53 (0.51) 0.302 & $1.21(0.42) 1$ \\
\hline & Control & $2.2(0.6)$ & $2(0.72)$ & $1.4(0.5)$ \\
\hline \multirow{3}{*}{$\begin{array}{l}\text { Use of sleep } \\
\text { medication }\end{array}$} & MAT & $1.8(1.3)$ & $0.91(1.10) 0.001 *$ & $0.73(1.08) 0.046$ * \\
\hline & CBT & $1.9(1.4)$ & 1.21 (1.82) 0.124 & $1.73(0.89) 0.773$ \\
\hline & Control & $1.3(1.4)$ & 1.55 (1.39) & $1.1(1.07)$ \\
\hline \multirow{3}{*}{$\begin{array}{l}\text { Day time } \\
\text { disfunction }\end{array}$} & MAT & $1.3(1)$ & 0.59 (0.59) $0.01 *$ & $0.45(0.60) 0.001 *$ \\
\hline & CBT & $1.7(1)$ & 1.05 (0.85) 0.803 & 1.05 (0.85) 0.467 \\
\hline & Control & $1.4(1.1)$ & $1.3(0.92)$ & $1.55(0.76)$ \\
\hline \multirow{3}{*}{$\begin{array}{l}\text { Quantity of } \\
\text { specimen }\end{array}$} & MAT & 22 & 22 & 22 \\
\hline & CBT & 22 & 19 & 19 \\
\hline & Control & 22 & 20 & 20 \\
\hline
\end{tabular}

* Effectiveness 
The Effectiveness of Targeted Music Therapy Intervention and Cognitive-Behavioral Therapy on Sleep Quality and Symptoms of Insomnia Disorder in seniors

Table 2. analysis of Covariance (ANCOVA) on marks of post-test \& follow-up "overall quality of sleep with control of pre-test effect, between MAT, CBT \& control Group”.

\begin{tabular}{ccccccccccc}
\hline \multirow{2}{*}{ Source } & \multicolumn{4}{c}{ Post-test } & \multicolumn{5}{c}{ Follow-up } \\
& SS & DF & MS & F & P $<$ & SS & DF & MS & F & P< \\
\hline Oqs* & 123.88 & 1 & 123.88 & 28.98 & 0.001 & 84.29 & 1 & 84.29 & 18.78 & 0.001 \\
Group & 356.04 & 2 & 178.02 & 41.64 & 0.001 & 429.30 & 2 & 214.65 & 48.05 & 0.001 \\
Error & 243.67 & 57 & 4.27 & & & 254.62 & 57 & 4.47 & & \\
Total & 7001 & 61 & & & & 6809 & 61 & & &
\end{tabular}

* Overall quality of sleep (Pre-test)

Table 3. Codes of multivariate in dependent Variables Covariance analysis (Sub Variables) in post-test \& follow-up.

\begin{tabular}{|c|c|c|c|c|c|c|c|c|c|c|}
\hline \multirow[b]{2}{*}{ Effect } & \multicolumn{5}{|c|}{ Post-test } & \multicolumn{5}{|c|}{ Follow-up } \\
\hline & 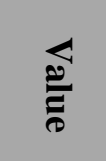 & $\mathbf{F}$ & 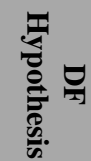 & 䀞 & $\mathbf{P}<$ & 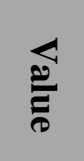 & $\mathbf{F}$ & 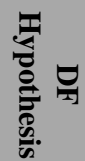 & 罢 & $\mathbf{P}<$ \\
\hline Pillai's trace & 0.703 & 3.56 & 14 & 92 & 0.001 & 0.94 & 5.79 & 14 & 92 & 0.001 \\
\hline $\begin{array}{l}\text { Wilke’s } \\
\text { lambada }\end{array}$ & 0.365 & 4.2 & 14 & 90 & 0.001 & 0.23 & 6.96 & 14 & 90 & 0.001 \\
\hline Hotelling trace & 1.55 & 4.88 & 14 & 88 & 0.001 & 2.61 & 8.22 & 14 & 88 & 0.001 \\
\hline Roy’s target & 1.42 & 9.34 & 7 & 46 & 0.001 & 2.30 & 15.12 & 7 & 46 & 0.001 \\
\hline
\end{tabular}

Table 4. Results of multivariate Covariance analysis for dependent Variable consideration (Sub Variables) in post-test \& follow-up.

\begin{tabular}{|c|c|c|c|c|c|c|c|c|c|c|}
\hline \multirow{2}{*}{$\begin{array}{l}\text { Dependent } \\
\text { Variable }\end{array}$} & \multicolumn{5}{|c|}{ Post-test } & \multicolumn{5}{|c|}{ Follow-up } \\
\hline & SS & DF & MS & $\mathbf{F}$ & $\mathbf{P}<$ & SS & DF & MS & $\mathbf{F}$ & $\mathbf{P}<$ \\
\hline $\begin{array}{l}\text { Subjective sleep } \\
\text { quality }\end{array}$ & 7.26 & 2 & 3.63 & 11.81 & 0.001 & 16.47 & 2 & 8.24 & 23.86 & 0.001 \\
\hline Sleep Latency & 6.42 & 2 & 3.21 & 8.49 & 0.001 & 8.75 & 2 & 4.38 & 15.12 & 0.001 \\
\hline Sleep Duration & 5.39 & 2 & 2.70 & 14.98 & 0.001 & 5.96 & 2 & 2.98 & 10.88 & 0.001 \\
\hline Sleep efficiency & 13.33 & 2 & 6.67 & 9.29 & 0.01 & 28.97 & 2 & 14.49 & 23.85 & 0.001 \\
\hline $\begin{array}{l}\text { Sleep } \\
\text { disturbance }\end{array}$ & 2.19 & 2 & 1.09 & 4.53 & 0.015 & 0.13 & 2 & 0.07 & 0.22 & 0.805 \\
\hline $\begin{array}{l}\text { Use of sleep } \\
\text { medication }\end{array}$ & 7.84 & 2 & 3.92 & 6.33 & 0.003 & 6.47 & 2 & 3.24 & 3.24 & 0.047 \\
\hline $\begin{array}{l}\text { Day time } \\
\text { disfunction }\end{array}$ & 3.68 & 2 & 1.84 & 5.63 & 0.006 & 10.8 & 2 & 5.40 & 11.30 & 0.001 \\
\hline
\end{tabular}


Table 5. Summary Comparison of our results with other researchers in the overall quality of Sleep and it's Subscales.

\begin{tabular}{|c|c|c|c|c|c|c|c|c|c|}
\hline \multicolumn{2}{|c|}{ Researchers } & 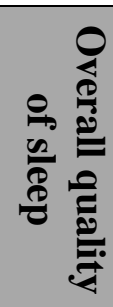 & 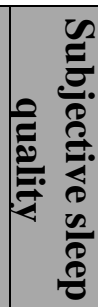 & 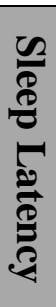 & 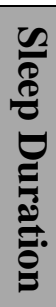 & 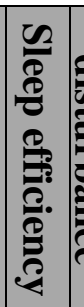 & 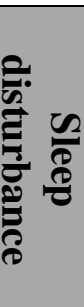 & 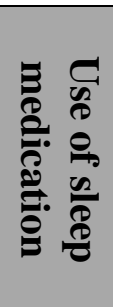 & 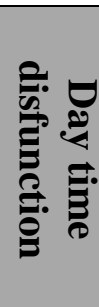 \\
\hline \multirow{2}{*}{$\begin{array}{c}\text { MAT } \\
\text { CBT }\end{array}$} & \multirow{2}{*}{ Mottaghi et al } & + & + & + & + & + & - & + & + \\
\hline & & + & + & + & + & + & - & - & - \\
\hline \multirow{5}{*}{ 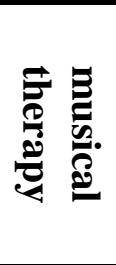 } & Harmat et al [30] & + & + & + & + & - & + & - & - \\
\hline & Hernadez-Ruiz [31] & + & + & + & - & - & - & + & - \\
\hline & Kullich et al [32] & + & + & + & + & - & - & - & - \\
\hline & Lai \& Good [3] & + & + & + & + & + & - & - & + \\
\hline & Zimmerman et al [33] & + & - & - & - & - & - & - & - \\
\hline \multirow{7}{*}{ 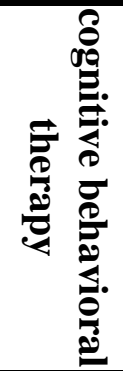 } & Ahmadi et al [34] & + & + & + & - & + & + & - & - \\
\hline & Siversten et al [35] & + & + & - & + & + & - & - & - \\
\hline & Jacobs [36] & - & - & + & - & + & - & - & - \\
\hline & Berger et al [37] & + & - & - & - & + & - & - & - \\
\hline & Edinger et al [38] & + & - & + & - & + & - & - & - \\
\hline & Riedel \& Lichstein [39] & + & - & + & - & + & - & - & - \\
\hline & Marin et al [40] & + & + & - & - & + & - & + & - \\
\hline
\end{tabular}

\section{+ Effectiveness - No Effectiveness}

\section{DISCUSSION AND SUMMERY ON FINDINGS}

Due to the fact that the aim of the present study is to analyze the effectiveness of music therapy and cognitive-behavior therapy on the overall quality of sleep and the indexes of sleep quality including subjective sleep quality, sleep latency, sleep duration, sleep efficiency, sleep disorder, taking sleep medication and daytime dysfunction in seniors. The result shows that music therapy and cognitive-behavioral therapy can become a proper method in improving the overall quality of sleep and primary insomnia disorder.

Music Therapy Researches: In Hungary Harmat at el. performed their treatment on scholars with insomnia disorder for 45 minutes in 3weeks period before going to sleep [22], while Hernandez in America performed his treatment on women with insomnia disorder for 20 minutes every day before going to sleep alongside relaxation [30] Kullich at el. in Austria performed their treatment on patients with back pain and insomnia once a day for 3weeks period alongside sleep hygiene and relaxation [31], Lai and Good in Taiwan applied their treatment on seniors suffering from insomnia disorder for 45 minutes for 3weeks period alongside sleep hygiene and relaxation [3], Zimmerman at el. in America applied his treatment on patients who went under coronary artery surgery suffering from insomnia disorder using audio or video music for 30 minutes, 2 times a week in the afternoon or early evening before bedtime [32]. All these researches shows that music therapy causes in developing and improving sleep quality and some 


\section{The Effectiveness of Targeted Music Therapy Intervention and Cognitive-Behavioral Therapy on Sleep Quality and Symptoms of Insomnia Disorder in seniors}

of its subscale indexes. Based on the 5 mentioned music researches, the studies that are mostly consistent with the result of this study are overall sleep quality with 5 similar cases, subjective sleep quality and sleep latency with 4 similar cases, sleep duration with 3 similar cases, sleep efficiency, sleep disorder, using sleep medication and daytime dysfunction with 1 similar case, respectively. Cardiovascular problems, high blood pressure, diabetes and arthritis are among the common seniors problems that affect both sleep disorder scales and daytime dysfunction. According to music intervention in this study, using sedative and tonic themes in daily bases, it seems that this approach is beneficial in decreasing daytime dysfunction. In another term this finding is in harmony with the findings of one the other researcher.

Cognitive-Behavioral Studies:The treatments that were applied by Ahmadi at el. by restricting sleep as one of the retailers of cognitive-behavioral intervention [33], Siveresten at el [34]. Jacobs at el. [35], Burger at el by improving sleep program one of the retailers of cognitivebehavioral intervention[36], Edinger at el. [37] Ridel and Lichstein with limitation of sleep another retailers of cognitive-behavioral intervention [24], and finally Marin at el. [38] all showed their findings on the effectiveness of cognitive-behavioral therapy and its retailers intervention on improving sleep quality and some other subscale indexes. Based on 7mentioned cognitive-behavioral therapy 6 external and 1 internal interventions, the findings with harmony of our research are as followed: Sleep quality with 7 similar cases, overall sleep quality with 6 similar cases, sleep latency with 4 similar cases, subjective sleep quality with 3 similar cases and sleep duration, sleep disorder, daytime dysfunction with 1 similar case are respectively had the highest coordination.

Due to theoretical background and previous studies, we can conclude that music therapy with its effects such as information processing [39], relaxation [3]-[40], decreasing daytime sleepiness[41], give meaning to life [42], setting mode [43], creating relations and therapeutic communication, becoming a hobby and being pleasant, brain balancing [23]-[44]-[45] and effecting emotions and feelings [23]-[46] and willingness to participate in medical treatment sessions, can actually causes in decreasing insomnia symptoms and developing sleep quality and cure insomnia. From another aspect, cognitive-behavior therapy also helps in curing the problem through sleep hygiene, sleep limitation [14], being out of wrong conditions [6], modifying thoughts and preventing the continuous elements that causes insomnia. [47]-[48]-[49]-[50]-[51][52]. Although this point should be noted that music therapy facilitate the way for other treatments with its proper interventions and approaches, since music therapy had no loss in members and the decreasing of daytime dysfunction and using sleeping pills are all among other privileges of this targeted intervention.

In final conclusion we can say that combining these two approaches music therapy and cognitive-behavioral therapy can become a beneficial step in curing insomnia. Among the advantages of these treatments are the quick effect of intervention, more effective results, avoiding sample lost in music therapy group which might be due to the fun and enjoyment of the treatment sessions. To be short, a fun and energetic day might lead to a good night sleep. According to the fact that prevention is better than cure, therefore it is necessary to use our psychological study regarding predisposing factors and screening to identify people who might be a candidate to have insomnia and put them under music treatment and cognitive-behavioral treatment as they enter aging. Finally regarding insomnia treatment we cannot solely depend on 
medication, since sleeping pills cannot be the only best and left solution. Taking medication pills must be used alongside music and cognitive-behavioral therapy. When these three interventions used all together, not only increases the effectiveness of the treatment and improves sleep quality, but also it makes it easier to stop or reduce medications. Senior's health centers can help in applying this project by using mental health professionals and music therapists alongside medical physicians and experts. Improvement of senior's sleep quality can have significant effects on individual, social, family, life quality dimensions and finally a better and more active presence in society.

RECOMMENDATION FOR FURTHER STUDIES AND LIMITATION OF THE STUDY This study suggests that for future studies scholars can use laboratory facilities to analyze sleep hormones and the changes during the process of treatment using Biofeedback device or Polysomnography to show more objective aspect of sleep, other art therapies, more effective music intervention by training and internship of the scholars, more experimental groups with more male participants and also combination therapy with other approaches such as logo therapy and long-term follow ups more that 6 months or even a year to achieve more efficient results. To be short, in explaining the results of this study we must also pay attention to the limitations as well, including small male sample size compare to female sample size which eventually leads the subject to be more cautious in generalizing the male results, and the fact that the subject was unable to perform double-blind study.

\section{ACKNOWLEDGMENTS}

The researchers of this study acknowledge their gratitude and appreciation to the research committee of Yasuj Azad University, Jahandedehgan adult day center in Shiraz and all the technical officials of this center. This project holds IRCT 2015041521754N3

\section{REFERENCE:}

1. Reimer M, Flemous W. Quality of life in sleep disorder. sleep medicine. 2003; 7(4): 335-349.

2. Bloom HG, Ahmad I, Alessi CA, Anccoldi-Israel S, Buysse DJ, Kryger MH, Philips BA, Thorpy MJ, Vitiello MV, Zee PC. Evidence-Based Recommendation for the assessment and Management of sleep Disorders in order persons. Journal of American Geriatrics Society. 2009; 57,761-789 .

3. Lai HJ, Good M. Music improves sleep quality in older adults . Journal of advanced Nursing. 2003; 49, 234-244.

4. Word Health report. Reducing risks, promoting Healthy life. Geneva: World Health organization 2002.

5. Breslau N, Rotht L. Rosenthal l, Andreski p. Sleep Disturbance and psychiatric Disorders: A longitudinal epidemiologic Study of Young Adults. Biological Psychiatry. 1996; 39, 4148.

6. American psychiatric Assocation. Diagnostic and Statistical Manual of mental disorders $\left(4^{\text {th }}\right.$, ed .,tex.rev )Washington , DC: Author. 2000.

7. Keplan \& sadock's. Synopsis of psychiatry. (9ht ed). Lippincott Philadelphia: Williams \&Wilkins 2003.

8. Marin CM, Bootzin R. et al. psycological and Behavioral treatment of insomnia: Sleep 2000; 629(11): 224-229. 
9. Ancoli-Israel, S. Insomnia in the elderly: A review for the primary care practitioners. Sleep 2000; 23.523-530.

10. Morin CM, Blais F, savard J. Are changes in belifes and attitudes about sleep related to sleep improvement in the treatment of insomnia: Behavior Research and Therapy. 2002; 40, 741-752.

11. Morin CM, Belanyer L, Bastien C, vallieres A. Long Term outcome of other discontinuation of Benzodiazepines for insomnia. Behavior Research and Therapy 2005; 43, 1-14.

12. Nowell pp, Mazumdar S, Buysse DJ, Dew MA, Reynolds CF, Kupfer DJ. Benzodiazepines and zolpidem for chornic insomnia: A Meta-analysis of treatment efficacy. Journal of the Amercan Medical Assocation. 1997; 278, 2170-2177.

13. Ancoli-Israel, S. Sleep and its Disorder in Aging population. Sleep Medicine 2009; 10, S7S11 . http://dx.doi.org/10.1016/J. sleep; 2009.07.004.

14. Espie CA, Macmahon KM, Kelly H.L, BroomFelied NM, Douglas NJ, Englemman HM, Mckinstry B, Morin CM, walker A, Wilson P. Randimized clinical effectiveness Trial of Nurse -Administrated small -Group cognitive Behavioral Therapy for persistent insomnia in general practice. Sleep 2007; 30, 547-584.

15. Montyomery P, Dennis J. Cognitive Behavioral interventations for sleep problems in adults aged60+Cochrane Database. Syst Rev 2003 (1): CD003161.

16. Vanhoudenhove L, Buyse B, Gabriels L, vandenergh O. Treating primary insomnia: Clinical effectiveness and predictors of outcomes on sleep Daytime function and health related quality of life .Journal of clinical psychology in medical settings 2011; 92,50-57.

17. Deniet G, Tiemens B, Lendemeijer B, Hutschemaekers G. Music-assisted relaxation to improve sleep quality: meta-analysis. Journal of advanced Nursing 2009; 65(7): 13561364.

18. Bardt J, Dileo, C. Music for stress and anxiety reduction in coronary heart Disease patients. The cocharane collaboration 2009; 2,1-77.

19. Edinger JD, Wohlyemuth W, Radtke R, Marsh G, Quillian R. Cognitive behavioral therapy for treatment of chronic primary in somnia: a randomized Controlled trial. Jama 2001; 285(14): 1856.

20. Edinger JD, Bonnet M, et al. Derivation of research diagnostic Criteria for in Somnia Report on an American Academy of sleep Medicine work group. Sleep 2004 ;27, 1567-1596.

21. Alvin J. Music in healing in Music Therapy. (pp 21-60). New York: Basic Books 1975.

22. Harmat L, Takacs J, Bodisz R. Music improves Sleep quality in Students. Journal of advanced Nursing 2008; 62, 327-335.

23. Koelsch S. Investigating Emotion with Music Neuroscientific Approaches. Annals of the New York Academy of Sciences 2005; 1080, 412-418.

24. Riedel B, Lichstein k. strategies for evaluating adherence to sleep restriction treatment for insomnia .Behavior research and therapy 2001; 39(2): 201-12.

25. Meyers LS, Gamst G, Guarino AJ. Applied Multivariate research: Design and interpretation. Calfonia, Thousand Oaks Sage Publications, Inc 2006.

26. Buijesse DJ, Reynolds CFIII, Monk TH, Berman SR, Kupfer Dj. The Pittsburgh sleep Quality index : a new instrument for psyehiatric practice and research. Psyehiatry Research . 1989; 28, 193-213.

27. Espie CA. Over coming Insomnia and Sleep problems: A self -help guide using Cognitive Behavioral Techniques . London. Robinson 2010. 
28. Martin G, Pear J. Behavior Modification: what it is and how to do it (4 ${ }^{\text {th }}$ ed) prentice Hall international . London. Amazo. co.U.K 1992.

29. Brance N, Kemp R. Snelyer R. SPSS for psychologists ( $4^{\text {th }}$ ed). Guide to Data Analysis Using. Amazo. co.U.K 2009.

30.Hernadez-Ruiz E. Effect of music therapy on the anxiety levels and sleep patterns of abused woman in shelters. Journal of music therapy 2005; 42,140-145.

31. Kullich W, Bernatzky G, Hesse HP, Wendtner F, likar R, klein G. Musictherapy -impact on pain , Sleep and quality of life in low back pain wiener. Mediziniscbe wocbenscbrift 2003.; 153, 217-221.

32. Zimmerman LC, Niereen J, Barnason S, Schmaderere M. The effects of music interventions on postoperative pain and sleep in Coronary artery by pass graft (CABG) patients. Scbolarly Inquiry for Nursing practice 1996; 10: 153-170.

33. Ahmadi S, Khakeh H, Mohammadi F, Fallahi M, Soltani PR. The effect of sleep restriction treatment on quality of sleep in the elders. Iranian Journal of Ageing 2010;5(2):7-15

34. Siversten B, Omrik S, pallesen S, Bjorratn B, Havik OE, Kvale C, Neilsen GH, Nordhus IH. Cognitive Behavioral therapy vs zopiclone for treatment of chronic primary insomnia in old adults . Jama 2006 ; 295,2851-2858.

35. Jacobs G, pace-Sehott E, Stickgold R, Otto M. Cognitive behavioral therapy and pharmacotherapy for insomnia: va randomized controlled trail and direct comparison Archives of Internal Medicine 2004; 164(17): 1888.

36. Berger A, Von Essen S, Kuhn B, Piper B, Farr L, Agrawal S, et al. Adherence, Sleep, and Fatigue outcomes ofther adjuvant Breast concer chemotherapy: Result of feasibility intervention study. One Nurse Society 2003. http://www. science.gov /topicpages/ c/cell+therapy+trials.html

37. Edinger JD, Wohlyemuth W, Radtke R, Marsh G, Quillian R. Cognitive behavioral therapy for treatment of chronic primary in somnia: a randomized Controlled trial. Jama 2001; 285(14): 1856.

38. Marin CM, Bootzin R, et al. Psycological and Behavioral treatment of insomnia. Sleep 2000; 629(11) C224-229.

39. Bengtsson SL, Ullén F. Dissociation between melodic and rhythmic Processing during Piano Performance from Musical Scores. Neurolmage 2006 ; 30, 272-284.

40. Han L, Li JP, Sit JW, Chung L, Jiao ZY, Ma WG. Effects of music therapy intervention on physiological Stress response and anxiety Level of mechanically Ventilated patients in China: a randomized Controlted trial. Journal of Clinical Nursing 2010; 19, 978-987.

41. Apter MJ. Reversal theory, Cognitive synergy and the arts. in W.R. Crozier and A.J. Chapman 28 M.J., Apter (Eds) Cognitive Processes in the perception of art (pp. 411-428). Amsterdam: North-Holland (Esevier) 1984b.

42. Frankl VE. Man's search for meaning. New York: Washington Boston. Square Press 1963.

43. Husain G, Thompson WF, Schellenberg EG. effects of musical tempo and mode on arousal mood ,and spatial abilities. Music perception 2002 ; 20, 151-171.

44. Johnsrude IS, Penhune VB, Zatorre RJ. Functional specificity in the right human auditory: Cortex for perceving pitch divectiax. Brain 2000; 123, 155-163.

45. Zatorre RJ, Belin P. Spectral and temporal processing in human auditory Cortex. Cerebral Cortex 2001; 11, 946-953.

46. Davidson RJ, lrwin W. The functional neuroanatomy of Emotion and effective style. Trendsin Cognitive Sciences 1999; 3, 11-21. 
47. Carny CE, Edinger JD. indentifying critical Dysfunctional beliefs about sleep in primary insomnia subtypes .Sleep 2006; 29, 325-333.

48. Carney CE, Edinger JD, et al. The Contribution of general anxiety to sleep quality ratings in insomnia subtypes . Sleep 2006; 29(SUPPI):A233.

49. Edinger JD, Fins AI, et al. Insomnia and eye of beholder : Are there clinical markers of objective sleep disturbances among adults with and without insomnia complaints . Journal of consulting and clinical psychology 2000; 68: 586-593.

50. Espie CA. Insomnia: Conceptual Issues in the Development persistence, and Treatment of sleep disorder in adults. Annu Rev Psycho 2002 ; 53: 215-243.

51. Harvey L, lnglis SJ, et al. Insomniacs reported use of CBT components and relationship to long-Term clinical outcome. Behaviour Research therapy 2002; 40(1): 75-83.

52. Morin CM. Insomnia: Psychological assessment and management, NewYork, Guliford press 1933. 